\title{
INERCIAS DEL SISTEMA EDUCATIVO MEXICANO
}

\author{
ROBERTO ANAYA \\ JOSÉ SUÁREZ
}

\section{RESUMEN}

$\amalg$ ste trabajo considera la cuestión de ciudadanía en tanto conjunto de características deseables para la interacción de las personas que conviven en el contexto y espacio nacional mexicano. Se discuten las relaciones de tensión existentes en la caracterización del sistema sociopolítico económico y cultural que matizan el espacio de convivencia, y se ensaya una configuración de ciudadanía pertinente a tal contexto. Se expone la ideología educativa como categoría de análisis sobre la formación de ciudadanía en estudiantes de educación superior del área de educación. Se realizó un contraste de orden cuantitativo entre la citada ciudadanía pertinente y los hallazgos empíricos obtenidos en dos instituciones educativas de diferente región del país. Entre los principales resultados se identifican matices vinculados a los momentos históricos de reconfiguración nacional y su influencia en el proyecto educativo nacional a través de las modificaciones en el artículo $3 .^{\circ}$ constitucional. Se encontraron aspectos que favorecen la idea de construcción de una ciudadanía de corte republicano, pero igualmente otros orientados a una de corte liberal. Finalmente, se analizó cómo las tendencias de transformaciones del sistema educativo han afectado la noción de ciudadanía que los futuros profesores se encuentran construyendo.

Conceptos clave: ciudadanía, democracia, ideología educativa, educación superior, estudiantes 


\section{INTRODUCCIÓN}

La globalización como un fenómeno actual pero vinculado a un largo proceso de transformaciones del capitalismo; implica y afecta al parecer a la totalidad de las formas de vida de las personas, muestra una dinámica que envuelve a entornos, naciones, instituciones e individuos independientemente de su deseo; arrasa, margina o anula cualquier diferencia o alternativa que atente contra el modelo monocultural y económico dominante que esta conlleva (Fariñas, 2004). Este fenómeno también intensifica las relaciones sociales a nivel mundial vinculando localidades distintas de tal manera que los acontecimientos locales son modelados por eventos que tienen lugar a muchas millas de distancia y viceversa (Giddens, 1991). Así, se puede esbozar un cuadro en donde, por un lado, existe una fuerza homogeneizadora que todo lo impacta, y por el otro, una intensa variedad de contextos económicos, políticos, sociales y culturales donde la primera ejerce su impacto.

En este sentido, los procesos globalizantes aparecen como formas destructivas de la vida social, que convierten en problemática a la sociedad como en nuestra época contemporánea ha sido concebida, es decir, un Estado-nación (Fariñas, 2004). Existen diversos elementos que entran en juego en tal binomio: una población determinada por un contexto particular; el conjunto de los diferentes bienes públicos que existen en el entorno físico que delimita dicho contexto, los cuales regularmente son administrados y normados por el Estado a través de las políticas públicas; y finalmente una forma de interacción al interior de estos Estadosnación y entre ellos, siendo la democracia la que actualmente goza de mayor aceptación y que de manera puntual implica en su contexto actual interacciones sociales y políticas bajo una dinámica de organización económica capitalista (Sartori, 2009).

Bajo esta dinámica, el modelo económico imperante crea un capitalismo global, una clase capitalista mundial y unas condiciones laborales y jurídicas que igualmente tienden a unificarse bajo una cultura hegemónica. Cuando todos estos elementos chocan contra las diversas realidades contextuales de la pobla- 
ción alrededor del mundo, se hace evidente que este fenómeno paradójicamente deja de lado otra serie de dinámicas que no se globalizan, como la intervención socioeconómica del Estado (en particular en cuanto a los objetivos del Estado de bienestar); los derechos sociales, económicos, culturales e incluso los derechos humanos que distan mucho de limitarse al derecho de propiedad privada, este último de particular interés para las dinámicas globalizantes capitalistas (Fariñas, 2004). Es así que este fenómeno implica un conjunto de retos en lo económico, político, social y cultural, al igual que una dinámica de cambio vertiginoso, mismos que las sociedades tienen que enfrentar desde sus peculiaridades y circunstancias específicas.

Un elemento tradicionalmente significativo por medio del cual las sociedades articulan esfuerzos con la finalidad de adaptarse a las transformaciones que experimentan, son los sistemas educativos. Existen distintas nociones y perspectivas desde las cuales se pueden analizar dichos sistemas, y en este trabajo se considera una relacionada con el compromiso institucional y social que estos tienen con la sociedad en general, que en el caso de México aparece reflejado en la Constitución mexicana y en las leyes que se desprenden de ella. Así, desde la noción de los Estados-nación, el empleo de un conjunto de recursos económicos y humanos al igual que de infraestructura, canalizados por medio de estos sistemas, constituyen un elemento esencial para desarrollar las características pertinentes en la población componente de tales naciones, de tal forma que les permita una participación articulada y funcional para enfrentar los procesos de transformación sociocultural, política y económica. Sin embargo, es importante considerar que las dinámicas de cambio de algunas instituciones de la sociedad obedecen a procesos complejos que no resultan compatibles con las transformaciones impuestas por las dinámicas globales capitalistas.

En este trabajo se considerará uno de los escenarios asociados a los sistemas educativos y las transformaciones que se pretenden lograr en las personas que por ellos transitan. El enfoque se dirigirá al aspecto de la actuación sociopolítica de las personas que integran una sociedad, en tanto una configuración de ciu- 
dadanía que resulte funcional con la democracia como forma de interacción dentro de los Estados-nación que, como se expresó anteriormente, es la que goza de mayor aceptación. Tomando en cuenta la diversidad institucional y cotidiana que participa en la formación de ciudadanía, nos ocuparemos de aquellas características que se espera desarrollen los estudiantes dentro de los sistemas educativos, orientándonos en analizar aquellas necesarias para los futuros profesores que integrarán tal sistema, donde serán actores centrales en esos procesos de formación.

Para ello se considera la siguiente ruta. Primeramente se planteará el asunto de la democracia como una forma de convivencia sociopolítica que se pretende vincular a la dinámica del sistema capitalista global actual, así como la caracterización pertinente que supondría una ciudadanía implicada con ambos. En un segundo momento, se realizará una breve síntesis de las transformaciones que ha sufrido la propuesta de desarrollo del conjunto de valores que es impulsado dentro del sistema educativo mexicano en relación con la formación de ciudadanía, así como de los objetivos perseguidos en este mismo aspecto y las modificaciones que se han observado en el artículo 3. ${ }^{\circ}$ de la Constitución Política de los Estados Unidos Mexicanos, en el cual, como se sabe, están suscritos los lineamientos centrales que marcan el proyecto educativo nacional. Posteriormente, se expondrá el concepto de ideología educativa, así como los tipos que derivan de ella en función del posicionamiento político y social que son analizados dentro del propio concepto. A través de esta aproximación, se puede concebir una forma de caracterizar el sistema educativo a lo largo de los diversos momentos históricos que le han dado origen. En un cuarto momento, se presentarán los resultados de dos estudios en diferentes entidades de la república mexicana, orientados a examinar las ideologías educativas y su vinculación con la cuestión de la formación de ciudadanía. Estos cuatro momentos se vinculan con tres niveles de análisis. Primero, la tensión existente entre un sistema económico capitalista y una forma de interacción sociopolítica democrática y su consecuente vinculación con la ciudadanía; segundo, la pretensión de formación de ciudadanía desde el sistema educativo para dar respuesta a la tensión 
antes mencionada; y tercer nivel, la caracterización concreta de aspectos vinculados a dicha formación de ciudadanía mediante la noción de ideología educativa, así como el contraste entre dos instituciones educativas del norte y sureste mexicanos. Finalmente, se discute en torno a la transformación e inercias del sistema educativo observadas en la caracterización de las ideologías educativas expuestas en los estudios realizados.

\section{LA CIUDADANÍA IMPLICADA ENTRE LA DEMOCRACIA Y EL SISTEMA CAPITALISTA GLOBAL}

Partimos de una concepción clásica de la ciudadanía como el conjunto de derechos y obligaciones civiles, sociales y políticas que corresponden a los miembros de un Estado-nación y por medio de los cuales se establecen las relaciones entre los diferentes actores del mismo (Marshall y Bottomore, 2005); un análisis significativo de dicha concepción se encuentra en relación directa con dos aspectos, uno vinculado al fenómeno de la globalización: el capitalismo; y el otro a la caracterización de una forma de interacción sociopolítica asumida por los Estados-nación: la democracia.

En la consideración del primer aspecto, la existencia de asimetrías en los niveles de empoderamiento y apropiación de recursos de distinta índole es una caracterización que le ha acompañado a lo largo de sus diversas e históricas formas de manifestación (González, 1969). Así, la regla que permea distintos análisis del sistema capitalista en cualquiera de sus versiones, es la producción de una ganancia y el crecimiento del capital; claro está, bajo la fórmula de la acumulación en determinados sectores o categorías, lo que implica de manera inherente la separación de otros sectores o categorías de la opción de participación de tal ganancia y de su crecimiento. Es decir, la asimetría con una expectativa de equilibrio planificado es la esencia del sistema (De Giovanni, 1984). Por supuesto, ha existido una complejidad creciente en la configuración de los sistemas económicos alrededor de esta forma de organización, así como discusiones que redimensionan, reconceptualizan y toman posturas encontradas. Pero no es el objetivo de este trabajo adentrarse en un análisis del capitalis- 
mo, solo se pretende destacar la naturaleza, si no opuesta a la democracia, al menos distintiva de un sistema económico que comprende ciclos de crecimiento y contracción del capital, mismos que generan crisis en torno a las cuales gira el fenómeno de la globalización (Rapoport y Brenta, 2010).

Para la consideración de la democracia como segundo aspecto vinculado a la formación de ciudadanía, se debe considerar la existencia de un conjunto de actores diversos que componen el sistema sociocultural, político y económico delimitado por la noción del Estado-nación. Esta diversidad supone una variabilidad de intereses que deben encontrar la manera de interactuar, competir y resolver los conflictos que de forma natural se gestan al interior de tales procesos, para lo cual es necesaria una participación sustentada en la diferencia y reconstrucción de una identidad colectiva (Touraine, 2002). Así, el régimen de gobierno democrático supone la búsqueda de un equilibrio entre el ejercicio del poder desde arriba, el cual resulta necesario para la eficacia del régimen, y la participación de los grandes sectores de la sociedad, en donde también se considere el asunto de la tiranía de las mayorías (Sartori, 1994). Tres características significativas de un régimen democrático se implican aquí: la competencia por el poder a través de las reglas establecidas, la cual supone una capacidad de dirección de todo el régimen. La pluralidad de características de los grupos que se organizan para competir por dicho poder, o bien para influir sobre su ejercicio en toda la configuración o algunos segmentos (económico, político y social) del sistema. Y la consideración de que mantenerse al margen de participar (sujetos o grupos) en esta dinámica implica de cierta manera renunciar a tener influencia sobre el sistema (Dahl, 1989 y 2003).

En este escenario, atendiendo de nueva cuenta la formación de ciudadanía y con el objetivo de vincular este elemento al análisis de los dos aspectos anteriores, resulta oportuno considerar tres formas de configuración o modelos de ciudadanía desde la perspectiva democrática occidental: liberal, republicana y radical (Escalante, 1992; Olvera, 2008).

El modelo de ciudadanía liberal destaca el papel de las garantías individuales, el respeto del orden jurídico y la tolerancia, 
asignando una función central a la noción de libertad individual en sus sentidos positivo y negativo, en donde el ciudadano debe hacerse responsable de su bienestar personal y de la protección contra aquellos riesgos que enfrente (Newman, 2005).

Por su parte, el modelo republicano se enfoca en la virtud ciudadana y se orienta por la convicción de la existencia de un bien público que persigue la igualdad, el cual se encuentra más allá de los intereses particulares de cada uno de los miembros de su comunidad política, con lo que las obligaciones de la ciudadanía son mayores, pues de la acción participativa del ciudadano depende el bienestar de la colectividad (Knight y Harnish, 2006).

El modelo radical, en tanto, se articula alrededor de nociones como la participación, la justicia social y el autogobierno; ahí la ciudadanía y su participación se convierten en una forma de batalla y vida por medio de la cual los individuos logran que se acepten sus posiciones y se modifiquen las decisiones públicas (Mouffe, 1992).

De la breve exposición de los elementos anteriores emerge una interrogante, ¿cuál de los tres modelos de ciudadanía resultaría con una correspondencia menos accidentada respecto de las tensiones que surgen entre el capitalismo y la democracia en función de sus naturalezas?

Analizando la cuestión por el lado del capitalismo, encontramos la existencia de diversas entidades participantes, que en una concepción convencional implica a los poseedores de los medios de producción, los poseedores de la fuerza de trabajo en tanto mercancía, los consumidores, productores, distribuidores, etcétera. E igualmente se identifica que las asimetrías en la configuración del sistema económico son deseables e incluso se propician, lo que resulta consecuente en virtud del espíritu del sistema: la obtención de ganancia con un incremento sostenido, al igual que la esencia del tipo de competencia que lo permea, ganar-perder. Lo anterior encuentra cierta confirmación en los ciclos recurrentes de expansión y contracción del capital y en los períodos de crisis económica que históricamente le han caracterizado y que supondrían una capacidad del sistema para reequilibrarse. Desde esta perspectiva, la resolución de las crisis se puede buscar por 
dos vías: una orientada a la liberalización del mercado que por medio de sus leyes naturales regulatorias a través de una mano invisible reestablecerá el equilibrio; por supuesto, existe una actuación que se difumina atrás de esta forma de regulación. Un ejemplo son las intervenciones militares de los Estados-naciones que son líderes de dicho sistema sobre otras naciones emergentes (Petras y Veltmeyer, 2004). Y otra vía que implica, por una parte, la intervención del Estado al interior de la nación que lo contiene, por medio de políticas sociales vinculadas a la noción del Estado de bienestar y ejemplificadas por las políticas keynesianas, en las cuales el Estado se concibe como ente regulatorio y articulador de todos los procesos socioeconómicos y culturales; y por otra parte, la protección sobre los efectos negativos que las dinámicas externas al Estado nacional pueden generar sobre sus contextos sociopolíticos y económicos (Rapoport y Brenta, 2010).

Ahora, por el lado de la democracia se destaca igualmente una diversidad de actores vinculados al sector estatal, al sector económico y al sector de la ciudadanía en su carácter civil. En esta diversidad, los individuos que se agrupan en tales sectores son cruzados por distintos roles, lo que propicia una creciente complejidad de reorganización en función de intereses semejantes, distintos u opuestos. Sin embargo, la esencia propia del régimen democrático se orienta a la búsqueda y aliento del equilibrio en la participación de los diversos actores con la intención de disminuir las asimetrías entre ellos, algo que se encuentra directamente vinculado con la competencia por el poder, el cual una vez logrado ofrece la oportunidad de tener mayor dirección e influencia en el sistema. En este sentido, los conflictos que originan tanto la competencia por el poder como los intereses opuestos, se buscarían resolver por medio de la interacción pacífica, el diálogo, el acuerdo y la búsqueda del bien común, donde resulta básica la noción de equilibrar la distribución del poder entre los distintos actores (Touraine, 2002; Sartori, 1994). Así, la democracia parece estar considerando la posibilidad permanente de que el poder sea distribuido asimétricamente, e incluso la existencia de individuos o grupos al margen del sistema de competencia y concentrados 
en aspectos de su vida cotidiana que poco tienen que ver con el funcionamiento del modelo global (Lipovetsky, 2002).

Desde este análisis, las tensiones entre capitalismo y democracia pueden identificarse en tres aspectos: primero, mientras que para el capitalismo la asimetría es deseable y se propicia, la democracia trabaja por el equilibrio en el poder y la disminución de las asimetrías. Segundo, mientras que la naturaleza de la competencia en el capitalismo es ganar-perder, para la democracia existe la opción de un bienestar común, donde incluso resulta deseable la renuncia a una ganancia individual por una ganancia menor pero de alcance colectivo. Y tercero, en la resolución de la crisis o el conflicto, mientras el capitalismo considera las fuerzas naturales del sistema o la intervención del Estado bajo una racionalidad técnica que se concibe en una objetividad ajena a los actores, la democracia atiende a la solidez de las instituciones que sustentan el sistema y desde la cual se propicia su autoequilibrio, o bien, considera la participación activa de los distintos actores con variaciones en la primacía del Estado o la sociedad civil bajo la racionalidad del diálogo, la deliberación y el consenso.

Pero también podemos identificar un punto de coincidencia entre ambas nociones: tanto el capitalismo como la democracia consideran la factibilidad siempre presente de que los recursos que se consideran valiosos desde ambos sistemas puedan ser distribuidos de manera asimétrica, y al suceder de manera extrema resultaría problemático para la subsistencia de ambos sistemas.

En función del análisis anterior, el grado de consolidación de un régimen democrático (Morlino, 1986, p. 13) puede considerarse un aspecto que profundice el examen de las tensiones anteriores con el tipo de ciudadanía. Entonces, en un régimen en transición política del autoritarismo a la democracia (Linz, 1978; Alcántara, 1992), sus instituciones aún no se encuentran en un estado de madurez. Y si consideramos que los actores económicos y el propio Estado, en buena medida urgidos por las dinámicas de la globalización, mantienen una articulación en la organización de sus intereses logrando acuerdos en aspectos que les fortalecen y en torno a los cuales cierran filas (por ejemplo, en el caso de la privatización de importantes recursos energéticos en México, gestiona- 
do por empresas transnacionales de los países más industrializados e impulsado por un amplio sector político) (Monreal, 2014), en tal dinámica, el sector en mayor desventaja sería el de la sociedad civil, en virtud de la diversidad que lo conforma y la condición en construcción de sus dinámicas organizativas. Esta característica es consustancial al pluralismo que supone la democracia.

En consecuencia, con estas caracterizaciones, una ciudadanía bajo un modelo republicano podría considerarse como una aproximación más provechosa que otra de orientación liberal. En la perspectiva republicana, la delimitación del bien público que persigue la igualdad debe incluir la pluralidad de perspectivas y responsabilidad mutua de los diversos sectores de una sociedad, mientras que la perspectiva liberal coloca el énfasis en la responsabilidad individual del bienestar personal. Asimismo, otros rasgos de una ciudadanía con orientación radical resultan atractivos para el empoderamiento del sector civil. De esta manera, una ciudadanía con tales rasgos implicaría una participación activa y de naturaleza política en la reducción de las asimetrías entre los distintos grupos o sectores de la sociedad, buscando igualmente el empoderamiento de los más vulnerables. Desde esta perspectiva, un cambio en la configuración del sistema sociopolítico y económico imperante se convertiría en una de las prioridades de dicha participación.

\section{SÍNTESIS DE TRANSFORMACIONES EN EL SISTEMA EDUCATIVO MEXICANO EN FORMACIÓN DE CIUDADANÍA}

Una vez establecida una aproximación a la caracterización deseable de la ciudadanía en relación con el sistema sociopolítico y económico, es importante considerar de manera sintética las transformaciones que el sistema educativo ha experimentado con respecto al asunto de la formación de ciudadanía. El objetivo es identificar la tendencia y el posicionamiento actual en cuanto a la caracterización pretendida de la citada ciudadanía.

En primer lugar, es importante destacar la consideración de la educación, en tanto institución, con respecto al desarrollo de la democracia, asunto que ha sido considerado desde el pensa- 
miento filosófico político clásico. Por ejemplo, ya Platón señalaba la conexión importante entre la educación y las instituciones fundamentales para la consolidación de una república. Siguiendo esta perspectiva, en una revisión general realizada por Sánchez (1996) sobre autores que abordan la relación de la educación con aspectos centrales de la democracia, como por ejemplo la gobernabilidad (Almond y Powell, 1996), se señala que en su mayoría los autores coinciden en la contribución que la educación hace a la consolidación y buen funcionamiento de la democracia. Es necesario para ello que la educación no se limite a la transmisión de conocimientos o aptitudes, sino que igualmente inculque y desarrolle valores y actitudes necesarios para el funcionamiento del sistema democrático. Desde este aspecto, se pueden plantear tres posturas cívico-éticas básicas de los sistemas educativos con respecto a la formación de ciudadanía. Una postura bajo una visión comunitaria que coloca el énfasis en la configuración, desarrollo y ejercicio de lo común, de un conjunto de valores y principios éticos que sustentarán la dinámica democrática de una sociedad (Dewey, 1995; Rawls, 1996). Otra postura de neutralidad liberal, que sostiene la importancia de que la educación no favorezca algún grupo de valores específicos, sino que este aspecto debe ser considerado de la competencia privada de lo familiar, que sin duda se encuentra dividida entre distintos posicionamientos (Ackerman, 1980). Y la tercera postura, de un pluralismo segmentado, que implica la clarificación de valores basándose en dos principios: ayudar a los alumnos a entender y desarrollar sus propios valores e inculcar respeto por los valores de otros; ambos, en función de los múltiples grupos que conforman a la sociedad. Sin embargo, este tercer posicionamiento ya implica un conjunto de ciertos valores como la racionalidad, la libertad, la igualdad, la tolerancia, la dignidad humana y respeto y aprecio por la pluralidad (Hayek, 1960). 


\section{LA INTEGRACIÓN DEL DESARROLLO DE VALORES EN LOS OBJE- TIVOS DE FORMACIÓN DE CIUDADANÍA DENTRO DEL SISTEMA EDUCATIVO: BREVE RECORRIDO HISTÓRICO}

En la breve descripción de las tres perspectivas anteriores, es factible identificar una vinculación entre la caracterización de una ciudadanía pertinente (republicana a radical) con la configuración de la democracia que actualmente se presenta en México (en transición), y dos perspectivas del posicionamiento y orientación de valores que los sistemas educativos podrían asumir (con base en lo comunitario y en un pluralismo segmentado), destacándose en dicha vinculación la igualdad en el bienestar colectivo como un valor comunitario, pero puntualizando diversos escenarios deseables para la diferencia. Con este referente, resultará significativa una aproximación a las transformaciones del sistema educativo por medio del recorrido histórico de la propuesta de desarrollo y asunción de valores que se identifican en la política educativa mexicana y que finalmente se han vertido en el artículo 3. ${ }^{\circ}$ de la Constitución Política de los Estados Unidos Mexicanos. Este recorrido tiene como objetivo identificar los momentos que fueron configurando la caracterización ideológica del sistema educativo, y cuyas ideas permean en diversos grados la ideología educativa que se analizará más adelante.

El proyecto de la educación como uno de los medios para la formación de ciudadanía aparece en los albores del Estado mexicano (Barba, 2004). La Constitución de 1824 marca la apertura del proyecto de conformación de una sociedad que en su dimensión política requería de manera prioritaria la aproximación a la formación moral del ciudadano en la emergente nación. Ya en ese contexto se reconoce la importancia que tiene la educación como asunto público, en particular en cuanto al valor que tiene para el progreso de los individuos y la sociedad. También se reconocen y resaltan principios que daban origen al nuevo proyecto de nación, pero que continúan vigentes en función de la caracterización actual de México; por ejemplo, el reconocimiento de la dignidad humana, la igualdad ante las leyes, la libertad y la responsabilidad por su ejercicio. El marco de referencia se integraba 
por tres elementos: el liberalismo, que daba origen a la noción de independencia; un republicanismo federal que articulaba la perspectiva de integración de la nueva nación; y el papel sustancial de los ciudadanos que la constituirían. En esta primera etapa de los antecedentes que en otro momento darían origen al sistema educativo, los objetivos perseguidos giraban alrededor del fortalecimiento de la transición desde las relaciones monárquicas coloniales a la nueva vida independiente por medio de un gobierno justo y la moral ciudadana (Barba, 2004).

En la alborada del proyecto educativo nacional se puede observar que los valores inicialmente, y después la política educativa, entran en una dinámica particularmente importante cuando de momentos de inestabilidad social se trata. Este escenario de cambio y transformación se extendió igualmente al siglo XX, lo que fue determinando la emergencia de ciertos valores. Al comenzar ese siglo, la cuestión educativa estaba vinculada con la identidad cultural de la nación, en una tensión entre la tradición heredada de España y el proyecto progresista del capitalismo liberal europeo y sajón (Llinás, 1978; Meneses, 1988).

A medida que el siglo XX avanzaba, se fortalecía el proyecto de desarrollo capitalista y la aspiración social por la modernidad política en un Estado democrático. Igualmente, se continuaba luchando para establecer junto al progreso a la justicia social. El Estado mexicano asumía la función educativa con la expectativa de que la propia educación contribuiría de manera puntual a la integración y al desarrollo; así, en la segunda década del siglo se impulsó la revisión y expansión del servicio educativo (Barba, 2003). Entonces, con un Estado cuyo poder se encontraba fortalecido sobre la sociedad civil producto de la revolución mexicana (Meyer, 1992), y la esperanza puesta en la educación para promover la integración sociocultural y el progreso económico, se dio origen a la Secretaría de Educación Pública (SEP). De esta forma, al encontrarse en un momento clave la fundación de la patria y con la articulación de un proyecto global como la SEP, se comenzó con la difusión de los valores nacionales para modelar la conciencia colectiva de un país y despertar la lealtad de los habitantes hacia el Estado-nación (Vázquez, 1975). 
Los valores que se asumieron para la integración de la nación y sirvieron de directriz a la educación mexicana fueron cinco: la escuela, un resumen de la experiencia de la humanidad; comprensión de la hispanidad como una cultura incluyente; formación del mexicano capaz de bastarse por sí mismo y servir a los demás; uso de la técnica sin detrimento del espíritu; y acercar la ciencia y el saber a la realidad mexicana para conocerla y promover la transformación social (Llinás, 1978). Así, al inicio de este proyecto se promovía intensamente la participación social, pero en la evolución del régimen el Estado subordinó la atención de las necesidades de la sociedad y su participación a proyectos corporativistas (Barba, 2003). En concreto, se impuso la dirección del Estado sobre la participación de la sociedad.

Las dinámicas anteriores se fueron sedimentando durante el siglo XX y se mostraron tres tendencias jurídicas en la definición de la educación, las cuales quedaron plasmadas en las modificaciones al artículo $3 .^{\circ}$ constitucional. La primera era hacer más explícitas las orientaciones de los valores asumidos. Con la aprobación en 1916 y su publicación el 5 de febrero de 1917, el nuevo texto del artículo $3 .{ }^{\circ}$ reiteraba que: la enseñanza sería libre, que la educación oficial así como la que se brindaba en los servicios particulares en primaria sería laica y estaría sujeta a vigilancia oficial, e igualmente que la educación primaria sería gratuita (Barba, 2003).

La segunda tendencia impulsada bajo la presidencia del general Lázaro Cárdenas, era hacer más extenso el ámbito valoral colectivo y establecer fuertes limitaciones a los particulares. Dos reformas al artículo 3. ${ }^{\circ}$ en 1934 y 1946 resaltaban una naturaleza socialista de la educación y la preeminencia de la unidad nacional y el amor a la patria sobre prejuicios o fanatismos religiosos. Se posicionó una concepción racional del universo y la vida social, al igual que los derechos humanos, la solidaridad internacional, la justicia y la paz; asimismo, aquellos valores asociados al sistema educativo que favorecerían el desarrollo armónico de las facultades de las personas (Cámara de Diputados, 2003; Barba, 2003). En los años setenta, aun cuando no se reflejó en modificaciones al artículo $3 .^{\circ}$, se planteó una reforma al sistema educativo mexicano, y a pesar que no fue de facto una reforma esen- 
cial (Ornelas, 1995), de alguna forma suministró elementos que matizarían las posteriores políticas educativas y su perspectiva acerca de los valores. En ella se ratificaba la idea de la educación como proceso personal y social. El primero debía ajustarse a los cambios que experimentaba el país y al desarrollo científico y tecnológico mundial (Latapí, 1989). Mientras tanto, el proceso social ya no se consideraba un factor autógeno de desarrollo social, sino condicionado por otros factores, dentro de los cuales el trabajo en valores que inculca la escuela era una contribución importante. Es significativa la consideración anterior en un momento de resistencias a reformas económicas y sociales; en la reforma educativa de 1980 se esbozaron en leyes para descentralizar la función social de la educación entre los niveles de gobierno federal, estatal y municipal, siendo responsable cada uno para fijar aportaciones económicas (Cámara de Diputados, 2003).

La tercera tendencia jurídica se encuentra al final del siglo XX, en el sexenio de Salinas (1989-1994) y dentro del proyecto nacional de modernización social y política, donde se eliminaron las restricciones a los particulares y a las corporaciones religiosas (Art. 3. ${ }^{\circ}$ constitucional, fracc. VI, inciso a, y fracc. II). Para la década de los ochenta, ya impuesta la tendencia neoliberal y con motivo de la crisis financiera de 1982, se inició una reforma del Estado y de la economía (Poder Ejecutivo Federal, 1983), que igualmente incluía una reforma a la educación, la cual de hecho se venía gestando desde la década anterior. En ella se contenían elementos que perduran en el presente y que afectarían los valores que se implican en la educación, destacando el de la calidad y los indicadores cuantitativos. Así, el asunto de los valores que la educación debía inculcar se encontraba implícito en los objetivos del desarrollo y del cambio educativo.

Los valores que a partir de ese momento guiaban a la educación como institución se mantuvieron a pesar del significativo evento para el avance de la democracia nacional ocurrido a inicios del siglo XXI. La alternancia en el ejecutivo federal en el año 2000, tras un largo período de 70 años de dominio del Partido Revolucionario Institucional (PRI), no logró alterar la tendencia de dirección tecnócrata de la educación. Con ello, las acciones 
del gobierno federal de ese entonces, a cargo del Partido Acción Nacional (PAN), se orientaron inicialmente a consolidar el control por el poder ejecutivo del sistema educativo (Diario Oficial de la Federación, 2004). También, en concordancia con las demandas sociales vinculadas a dicha alternancia, se resaltaron dentro de la normatividad del sistema educativo otros valores: como el aprecio por la pluralidad y la importancia de preservar las culturas indígenas (Diario Oficial de la Federación, 2003). Asimismo, se destacaron en planes y programas de estudio valores vinculados a la caracterización de una ciudadanía que fortaleciera el proceso democrático; como la participación política, el aprecio por la democracia, la resolución de conflictos por la vía pacífica, entre otros (SEP, 2008). Sin embargo, dos sexenios de alternancia en el ejecutivo federal (2000-2012) apenas reflejaron un tímido esfuerzo a nivel del discurso para impulsar valores vinculados a la democracia, en contraste con el fuerte respaldo que recibieron valores vinculados al desarrollo de un sistema económico bajo una óptica capitalista liberal. Por ejemplo, en la reforma al artículo 9. ${ }^{\circ}$ de la Ley General de Educación en el año 2012, valores como calidad educativa, procesos productivos y desarrollo económico son respaldados a través del apoyo ordenado a la investigación científica y tecnológica (Diario Oficial de la Federación, 2012). Con el retorno del PRI al ejercicio del ejecutivo federal en 2013, se promovieron otras modificaciones al artículo $3 .^{\circ}$ constitucional en su fracción IX, con un énfasis en la evaluación como herramienta para el logro de la calidad. Así, se decretó la creación del Sistema Nacional para la Evaluación Educativa y el Instituto Nacional para la Evaluación de la Educación (Diario Oficial de la Federación, 2013). Estos cambios antecedieron a una reforma educativa en el contexto laboral, donde actualmente se encuentran vigentes discusiones importantes, orientándose una de ellas a la recuperación del control del sistema educativo que tradicionalmente ha estado fuertemente influido por el Sindicato Nacional de Trabajadores de la Educación. En todo caso, el valor que se resalta para dicha reforma es el de la calidad educativa vinculada al logro de indicadores afines a las recomendaciones de organismos 
internacionales como el Banco Mundial o la Organización para la Cooperación y el Desarrollo Económicos.

En este breve recorrido temporal, se pueden apreciar a grandes rasgos tres momentos en la historia del sistema educativo mexicano, sobre todo en cuanto a la intención política y los valores que intentaban imbuir en la población (Ornelas, 1995). El primero, donde se enmarca la creación de la SEP como punto nodal de la consolidación de un sistema educativo gratuito, laico y bajo la tutela del Estado, con una visión que buscaba robustecer la identidad nacional por medio de valores culturales universales y un ímpetu civilizador vinculado al proyecto de unidad nacional. En un segundo momento destaca la función social de la educación y su dirección bajo el desarrollo del conocimiento científico, los valores nacionales y los derechos humanos, con lo que se impulsaron dos vertientes: una utilitarista, vinculada al fortalecimiento de la enseñanza tecnológica, y otra, un tanto populista, que asociaba la educación con la resolución de los problemas económicos, políticos y sociales. Y un tercer momento, orientado a la homogenización del sistema educativo, y donde la relación desarrollo educativo-desarrollo social ahora se plantea en función de factores externos y cambios globales, puntualizando los valores de la calidad y el desarrollo económico junto a la inclusión de la diversidad de contextos y la pluralidad de grupos que conforman a la sociedad mexicana. Estos tres momentos del sistema educativo y del artículo $3 .{ }^{\circ}$ constitucional han de considerarse también en relación con otros dos mandatos constitucionales correspondientes a los artículos 39 y 40, donde se establece la soberanía del pueblo para alterar o modificar la forma de gobierno y su voluntad de constituirse como nación en una república representativa, democrática, laica y federal (Cámara de Diputados, 2015).

Las actuales dinámicas globales del desarrollo económico y la competitividad internacional, por un lado, y las dinámicas sociopolíticas al interior de la sociedad mexicana por otro, imprimen en la orientación del sistema educativo dos perspectivas que se puntualizaron en los temas de la calidad para la competitividad global y la formación de ciudadanía para el fortalecimiento de la democracia. Mientras que la primera se convirtió en la ten- 
dencia que ha influido mayormente las transformaciones del sistema educativo, así como los valores reflejados en las reformas al artículo 3. ${ }^{\circ}$ constitucional y a la Ley General de Educación, la segunda logró asentarse en los mandatos constitucionales y la normatividad correspondiente. Sin embargo, la cuestión de la formación de ciudadanía nunca ha representado la canalización especial de recursos económicos para tal fin, como sí se concretó para el fortalecimiento del desarrollo científico y tecnológico por medio de programas a lo largo del sistema educativo, como en los casos del programa Enciclomedia en la educación básica y los fondos para fomentar la investigación científica y tecnológica en el nivel superior (SEP, 2006; Del Valle, 2014; Diario Oficial de la Federación, 2015).

Sin duda, estos momentos históricos se han asentado en el conjunto de creencias e ideas que sobre la educación tienen los profesores, de manera concreta en el aspecto de la educación como herramienta para la formación de ciudadanía. Con el fin de aproximarnos a ese aspecto, en el siguiente apartado se considerará el asunto de la ideología educativa y cómo ciertos tipos ideológicos estarían en mayor correspondencia con un modelo de ciudadanía, así como con las condiciones sociopolíticas y económicas imperantes.

\section{LA IDEOLOGÍA EDUCATIVA COMO CATEGORÍA DE ANÁLISIS DEL SISTEMA EDUCATIVO Y POSICIONAMIENTO POLÍTICO-SOCIAL}

Considerando que del término ideología se han ensayado múltiples usos y definiciones desde diversas disciplinas, en este trabajo se le emplea para dar cuenta del conjunto de ideas características de un grupo sobre un dominio social particular, en este caso los futuros profesores, y en relación con la educación. La ideología es un elemento importante que no solo hace referencia al sistema de creencias que predispone el comportamiento, sino igualmente a asuntos relativos al poder; entonces, la ideología tiene que ver con la legitimación del poder de un grupo, clase dominante o sistema social (Eagleton, 1997). Sin embargo, no se debe suponer que la 
ideología de un grupo, sector o clase se encuentra construida solamente por elementos ilusionistas con fines de control de la clase dominante, pues las ideologías para consolidarse deben transmitir una visión de realidad social que sea suficientemente reconocible para no ser rechazada de inmediato (Eagleton, 1997). Asimismo, la ideología en cierta medida representa en efecto la realidad, es decir, la manera en la que una persona vive sus relaciones con el conjunto de la sociedad, algo que de entrada no puede considerarse como verdad o falsedad y que por otro lado tiene una existencia material (Althusser, 1985). La ideología, entonces, se convierte en materia constitutiva importante de nuestra identidad, en nuestras creencias y suposiciones que aluden igualmente a nuestras relaciones afectivas y experiencias previas (Eagleton, 1997).

Una ideología educativa, quizá no siempre de forma consciente, ha sido construida en y por los maestros mexicanos; igualmente, se ha nutrido de diversas influencias filosóficas a lo largo de la historia de nuestro país (Navarro, 2006). En este sentido, dicha ideología nos aporta elementos sobre el conjunto de opiniones, actitudes y valores que acerca de la educación tiene el profesorado y que constituyen su perspectiva acerca de aspectos como el propósito de la educación, sus objetivos secundarios, el papel del alumno en el proceso de enseñanza-aprendizaje, la selección del conocimiento válido, la importancia del control disciplinario, la función social y profesional del maestro, los valores deseables a promover, la concepción de escuela como organización institucional y el papel que deben jugar en el diseño curricular de las experiencias educativas la comunidad en general, los padres de familia y el Estado (Loera, 2005; Arroyo, 1998; O’Neill, 1981). Con la anterior concepción de la ideología educativa, este trabajo considera que el conocimiento de las ideologías permite identificar la existencia o no de una sincronía entre las pretensiones del sistema educativo de formar cierto tipo de ciudadanía y algunas características que definen dicho sistema. Tales ideologías se distinguirían en el conjunto de ideas que los potenciales futuros profesores han articulado acerca de la educación y sus funciones en la sociedad.

El marco conceptual asumido (O'Neill, 1981), considera un acercamiento a un aspecto particular de los estudios de la prác- 
tica pedagógica: la relación de esta con los fines de la educación y su posición respecto a los valores deseables, el conocimiento válido, las nociones del alumno, de la escuela, del rol del propio profesor, del currículo idóneo y de la sociedad en general. Desprendiendo su propuesta desde la perspectiva de la filosofía política, vincula los tipos ideológicos propuestos con las diferencias básicas dentro de la filosofía moral, planteando seis filosofías políticas básicas. Tres posicionamientos definidos desde la perspectiva conservadora: conservadurismo reaccionario (autoritarismo antiintelectual), conservadurismo filosófico (autoritarismo intelectual) y conservadurismo social (convencionalismo autoritario). E, igualmente, tres posicionamientos definidos desde la perspectiva liberal: liberalismo político, liberacionismo político, y anarquismo político.

Así, desde un sistema básico de ética social séxtuple, reflejado a través de las correspondientes filosofías políticas, se desprende un modelo básico de seis ideologías educativas: tres conservadoras (fundamentalismo educativo, intelectualismo o racionalismo educativo y conservadurismo educativo); y tres liberales (liberalismo educativo, liberacionismo educativo y anarquismo educativo). Todas ellas implican una serie de posicionamientos morales y políticos con respecto a la conducción de la enseñanza y la escuela. A continuación se describirán de manera básica los seis posicionamientos (O’Neill, 1981).

I. Fundamentalismo educativo: es un conservadurismo básicamente antiintelectual, cuya meta es revivir los valores y concepciones pasadas del mundo y, por consecuencia, el propósito de la educación es confirmar que la forma tradicional de vida es la mejor, especialmente por sus bases morales. Se trata de ubicar los objetivos de la escuela en reformar la sociedad, volviendo a las tradiciones y buscando reconstruir la sociedad con base en una regeneración moral acorde con su origen; además, se busca transmitir la información y las habilidades necesarias para tener éxito en el orden social actual. En la educación mexicana, esta ideología educativa ha inspirado a los grupos económicos y religiosos tradicionalistas, que en esencia bus- 
can minimizar las consideraciones intelectuales y filosóficas, y tiende a fundamentar su posicionamiento por medio de una aceptación no crítica de las verdades reveladas o de los consensos establecidos socialmente.

II. Intelectualismo educativo: su meta consiste en identificar, preservar y trasmitir la verdad. Ubica los objetivos de la escuela en enseñar a los estudiantes a razonar y trasmitir sabiduría, procurando desarrollar competencias racionales y poniendo principal énfasis en la lógica deductiva. En México han coincidido en esta ideología tendencias religiosas confesionales, como la tradicionalmente impulsada por los jesuitas, y tendencias que en el porfirismo fueron oficiales y buscaban el cambio de las prácticas políticas existentes, con la intención de hacerlas más confortables o perfectibles, en función de un establecimiento esencial de los ideales intelectuales.

II. Conservadurismo educativo: su meta es preservar y trasmitir patrones establecidos de conductas sociales y por lo tanto dominantes. Ubica los objetivos de la escuela en motivar el entendimiento y aprecio de las instituciones y tradiciones culturales contemporáneas del grupo o de la sociedad y un profundo respeto por la ley y el orden. En México el conservadurismo laico ha sido explícito en los programas de ciencias sociales y en las declaraciones oficiales acerca de las expectativas que se tienen del producto educativo. En términos políticos, actualmente y en función del evento de la alternancia en el poder en el año 2000, el discurso se ha pronunciado en función de la transición democrática; sin embargo, hasta el momento no se han realizado cambios estructurales significativos para apoyar dicho discurso. La tendencia de esta postura es la de mantener un sistema político o social en su estructura vigente.

IV. Liberalismo educativo: su meta es promover una conducta personal efectiva en un mundo cambiante. Ubica los objetivos de la escuela en proveer a los estudiantes con la información y habilidades necesarias para que aprendan por ellos solos, además de enseñar a los estudiantes a resolver problemas prácticos mediante la metodología científica. En México, el actual discurso dominante es el liberalismo, en donde confluyen 
tendencias históricas como el pragmatismo, la ideología tecnócrata dominante de las actuales esferas políticas y el individualismo de las escuelas activas.

V. Liberacionismo educativo: su meta es concientizar a los oprimidos de su situación social objetivándoles su mundo, dándoles oportunidades de expresarlo desde su propia perspectiva y motivándolos a la acción social revolucionaria. Ubica los objetivos de la escuela en que esta debe ser un lugar de lucha política y de enfrentamiento por la liberación de las estructuras injustas. En México, esta ideología ha sido instrumentada por grupos no oficiales en experiencias de educación no formal, principalmente grupos inspirados en la filosofía educativa de Freire. Estas experiencias las han propiciado básicamente grupos religiosos reformistas, grupos socialistas cristianos, marxistas y algunos grupos de la tendencia sindical de oposición como la Coordinadora Nacional de Maestros, y definitivamente experiencias socioeducativas revolucionarias como el zapatismo. Sin duda, una perspectiva liberacionista aporta elementos sustanciales que fortalecerían un proceso de transición y consolidación democrática.

VI. Anarquismo educativo: su meta es deslegitimar la escuela como institución necesaria y proveedora de igualdad social. Ubica los objetivos de la educación en que el sistema formal de enseñanza debe ser abolido y reemplazado por un patrón de autoaprendizaje voluntario y un libre acceso a los materiales educativos; además, no considera un currículo obligatorio de estudio. En México, como en el resto de Latinoamérica, la filosofía educativa de Ivan Illich (1985) ha penetrado en algunos grupos, pero estos han ofrecido escasas experiencias alternativas a la educación y su impacto social ha sido mínimo. Sin embargo, están presentes como opción ideológica.

El modelo considerado en el presente trabajo no sugiere ser definitivo o invariable ni tampoco que los tipos ideológicos sean los únicos presentes e incluso significativos en la educación mexicana. Sin embargo, se establece su pertinencia con posturas claramente delimitadas en la literatura especializada en filosofía 
educativa (O'Neill, 1981), por lo que resulta consecuente asumir que en México existen instituciones educativas, sean públicas o privadas, que representan dichas ideologías con sus respectivas variantes.

Completado el planteamiento teórico-conceptual y definida la categoría de análisis central de este trabajo se propone, con base en la experiencia actual de la sociedad mexicana, una pertinencia funcional entre: a) un contexto económico globalizado imperante; b) un proceso sociopolítico de transición hacia la democracia; c) una caracterización de ciudadanía ubicada en la perspectiva republicana con aspiraciones radicales; y d) una orientación ideológica que considere un énfasis en los tipos liberal y liberacionista. La correspondencia funcional propuesta atiende a un modelo de naturaleza deductiva, por supuesto sujeto a discusión epistémica y contraste empírico que le permitan enriquecerse o modificarse.

\section{ESTUDIOS SOBRE LA IDEOLOGÍA EDUCATIVA EN UNIVERSIDA- DES DE DOS ENTIDADES FEDERATIVAS}

Con el objetivo de vincular la propuesta anterior con el referente empírico, en este apartado se realizará un contraste entre la caracterización de una ciudadanía coherente con el contexto actual y hallazgos empíricos sobre la ideología educativa, en los cuales se buscará evidencia sobre algunas condiciones dentro del sistema educativo para conformar tal ciudadanía. Asimismo, se realizará un contraste entre dos instituciones ubicadas en el norte y sureste mexicano, indagando sobre diferencias en las ideologías educativas de sus estudiantes, que podrían estar vinculadas a las distinciones socioeconómicas y culturales que caracterizan dichos contextos. Se observará el comportamiento de algunas variables sociodemográficas como el tránsito de los estudiantes dentro del sistema educativo, su edad y experiencia en el entorno laboral desde una perspectiva en la que cada contexto o condición ofrece interacciones sociopolíticas diferentes y matiza la configuración de su ideología educativa. También se considera en el estudio la influencia del género en tanto elemento de carácter social estructural. 
Para ello, se presentan los resultados de dos investigaciones realizadas en el subsistema de educación superior en las entidades federativas de Chihuahua y Veracruz. Los estudios se realizaron en la universidad pública más importante de cada estado. La Universidad Autónoma de Ciudad Juárez (UACJ) en el programa de Licenciatura en Educación del Departamento de Humanidades en el año 2012; y la Universidad Veracruzana (UV) en la Licenciatura en Pedagogía de la facultad del mismo nombre en el año 2015. Los estudios, de manera general, se orientaron a indagar sobre competencias cívicas y éticas, así como habilidades potenciales vinculadas a la formación de una ciudadanía democrática en los futuros profesionistas del sector educativo, en la idea de que tales competencias y potencialidades serán aspectos centrales en la implementación de programas educativos institucionales o esfuerzos comunitarios orientados a la formación de ciudadanía. Si bien los estudios incluyen otras instituciones participantes y categorías de análisis, como el razonamiento moral o las actitudes hacia conceptos vinculados a un sistema de régimen democrático por medio de la técnica del diferencial semántico, para este trabajo, en virtud de la temática seleccionada, solo se consideraron la ideología educativa y las instituciones referidas.

La información empírica se recopiló por medio del Inventario de Ideologías Educativas, instrumento fundado y elaborado en el modelo teórico antes expuesto (O'Neill, 1981; Arroyo, 1998; Loera, 2005), y empleado en otras investigaciones por Arroyo (1998) en la ciudad de Chihuahua; Contreras, Escobedo, Quintana y Valdés (2003) en el estado de Durango; Guzmán y Barraza (2004) en la ciudad de Chihuahua; Loera (2005) en un estudio nacional sobre evaluación cualitativa del Programa Escuelas de Calidad; y por Anaya (2009) en Ciudad Juárez. El inventario está diseñado primordialmente para el uso de educadores, educadores potenciales y aquellos involucrados primordialmente con la educación y asuntos educativos. La versión general consta de 104 afirmaciones de discriminación ideológica en la forma de preguntas tipo Likert, de las cuales 84 pertenecen a las 6 diferentes posiciones dentro de la filosofía educativa y las restantes 20 a dos escalas generales de confirmación (en ambos estudios presentados en 
este trabajo se utilizó la versión de los 84 ítems). Sus resultados permiten elaborar un perfil del individuo o del grupo de sujetos, destacando el tipo ideológico prominente y los valores relativos a los tipos ideológicos restantes. En cuanto a la validez y análisis de contenido en su construcción, se realizó un análisis factorial con la escala Guilford para interpretación, resultando una clara distinción factorial para cada una de las ideologías; asimismo, el instrumento ha sido piloteado y validado para maestros de educación básica en México por Heurística Educativa (Loera, 2005), manifestando los 84 ítems relativos a las seis posiciones ideológicas centrales una fiabilidad de .90 en el alfa de Cronbach.

Las muestras se definieron y seleccionaron bajo criterios (Hernández, Fernández y Baptista, 2006). Para el estudio en el estado de Chihuahua, se consideraron seis instituciones que cuentan con programas de formación de docentes o educadores y que conformaron una muestra de 495 casos, de los cuales se retoma para este trabajo el segmento procedente de la licenciatura en educación de la UACJ, con 122 casos. Para el estudio en el estado de Veracruz se consideraron cinco instituciones que igualmente cuentan con programas de formación docente, considerando una muestra general de 900 casos, de los cuales se retoma el segmento procedente de la facultad de pedagogía de la uv región Xalapa con 139 casos. Los estudiantes se seleccionaron bajo criterios de oportunidad, consentimiento de participación y con un avance en sus programas académicos de al menos el tercer semestre completo. Las dos universidades públicas seleccionadas para este trabajo, al ser las más importantes en sus entidades, consideramos que pueden ofrecer la configuración más dinámica en cuanto a la caracterización ideológica-educativa de sus estudiantes. Rasgos sociodemográficos básicos de ambas muestras se presentan en la tabla 1. 
Tabla 1. Configuración sociodemográfica de la muestra por instituciones

\begin{tabular}{lcccccccc}
\hline & \multicolumn{2}{c}{ Sexo } & \multicolumn{3}{c}{ Edad / años } & \multicolumn{2}{c}{ Procedencia } & Total \\
\cline { 2 - 8 } & $\begin{array}{c}\text { Hom- } \\
\text { bres } \%\end{array}$ & $\begin{array}{c}\text { Mujeres } \\
\%\end{array}$ & Media & $\begin{array}{c}\text { Rango } \\
\text { menor }\end{array}$ & $\begin{array}{c}\text { Rango } \\
\text { mayor }\end{array}$ & $\begin{array}{c}\text { Urbano } \\
\%\end{array}$ & $\begin{array}{c}\text { Rural } \\
\%\end{array}$ & $\begin{array}{c}\text { de } \\
\text { casos }\end{array}$ \\
\hline UACJ & 15 & 85 & 23 & 19 & 39 & 94 & 6 & 122 \\
\hline UV & 16 & 84 & 20 & 18 & 44 & 70 & 30 & 139 \\
\hline
\end{tabular}

Para analizar la información se elaboraron perfiles de los tipos ideológicos con la media aritmética como indicador de tendencia central, tanto para la muestra conjunta con ambas instituciones como para cada institución de manera independiente. También se realizaron correlaciones $r$ de Pearson de los tipos ideológicos con algunas variables sociodemográficas para la muestra general, y contrastes entre instituciones en función de otras variables sociodemográficas y los tipos ideológicos por medio de pruebas de hipótesis t de Student.

\section{RESULTADOS Y ANÁLISIS}

Un primer conjunto de resultados por medio de una correlación producto-momento de Pearson (tabla 2), se plantea en torno a las relaciones que se pueden identificar entre variables sociodemográficas y los comportamientos de algunos tipos ideológicos. La intensidad de las correlaciones se valoró con la escala interpretativa de Guilford: $0 \mathrm{a} \pm .20$ leve; $\pm 0.20 \mathrm{a} \pm .40$ baja; $\pm .40 \mathrm{a} \pm .70$ moderada; \pm .70 a \pm .90 alta; \pm \pm .90 a \pm 1.0 muy alta (O’Neill, 1981, p. 373).

En cuanto a la experiencia laboral previa (tiempo que los estudiantes antes del ingreso a su carrera o durante ella han dedicado a participar en actividades educativas de manera profesional), se puede observar una correlación negativa, leve pero significativa, con los tipos fundamentalista y racionalista. En relación con la edad, se identifica un patrón en donde a medida que esta se incrementa se presenta un distanciamiento de los tipos ideológicos conservadores (fundamentalista, racionalista y conservadurista), observándose estas correlaciones con una magnitud baja, mientras que en los tipos ideológicos liberales solo se observa este 
mismo comportamiento para el anarquismo, manteniendo dicha correlación un nivel de magnitud leve. Para el caso del nivel de estudios, se repite el mismo patrón observado en las ideologías de orientación conservadora con respecto a la edad, siendo estas correlaciones, si bien de magnitud baja, las más altas de todas las identificadas.

Este primer conjunto de resultados nos sugieren que la mayor experiencia laboral puede constituir un factor que haga a los individuos de la muestra tomar mayor distancia de algunos tipos ideológicos con orientación conservadora, mientras que el mismo efecto, con un nivel un poco más alto y para todo el espectro de ideologías de orientación conservadora, lo producen las variables de edad y nivel de estudios, siendo esta última la que logra generar el mayor efecto. Entonces, si bien el efecto es de leve a bajo, es posible observar un patrón en la influencia que este tipo de variables ejerce sobre las ideologías con orientación conservadora. Correlaciones con patrones semejantes se han identificado en otros estudios (Guzmán y Barraza, 2004; Anaya, 2009).

Tabla 2. Correlación producto-momento de Pearson de la ideología educativa con variables sociodemográficas (muestra general)

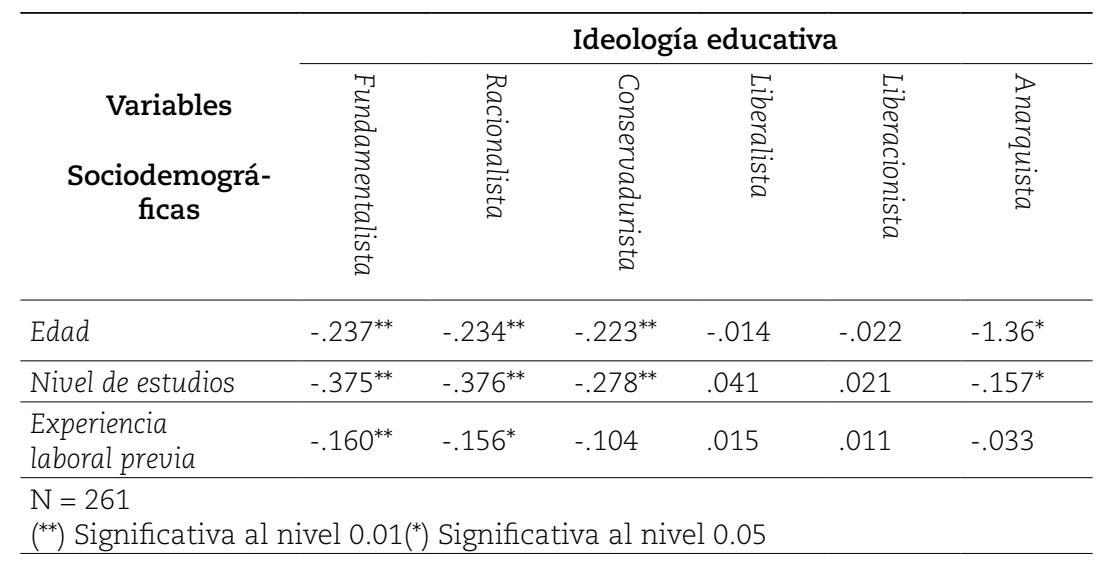

Un segundo conjunto de resultados (gráfica 1), presenta la configuración de un perfil de la muestra general que considera las magnitudes de los seis tipos ideológicos, describiendo la caracterización de la actuación sociopolítica que dicho perfil implicaría 
en relación con un posicionamiento del papel de la educación en la formación de ciudadanía. Se empleó la media aritmética como indicador para distinguir la magnitud de los tipos ideológicos, y con el objetivo de identificar diferencias entre ellos se realizaron pruebas t de Student para muestras relacionadas.

En primer lugar se puede observar el dominio del tipo ideológico liberalista por sobre los demás tipos, con un valor que duplica en magnitud y con diferencia estadística significativa al segundo tipo ideológico con mayor consolidación, el liberacionismo $\left[\mathrm{t}_{(260)}=\right.$ $16.664, \mathrm{p} \leq .01]$. Este segundo tipo, también con una diferencia significativa a su vez, casi duplica la magnitud del valor del tercer tipo más desarrollado, el conservadurismo $\left[\mathrm{t}_{(260)}=5.628, \mathrm{p} \leq .01\right]$. Entre este tercer tipo con mayor puntaje y el siguiente en magnitud (el racionalismo), no existe diferencia estadística, por lo que se puede expresar que ambos se encuentran presentes en la misma magnitud. Los tipos ideológicos que presentan la menor magnitud son el anarquismo, cuya magnitud es estadísticamente igual que el racionalismo, y el fundamentalismo, que incluso se presenta con un valor negativo, lo que supone un alejamiento de esta perspectiva ideológica. Otras investigaciones igualmente han reportado este tipo de diferencias donde liberalismo y liberacionismo son los tipos ideológicos más consolidados, seguidos de conservadurismo, racionalismo, anarquismo y un fundamentalismo con valor negativo (Arroyo, 1998; Loera, 2005; Anaya, 2009). 
Gráfica 1. Perfil de ideologías educativas para la muestra general

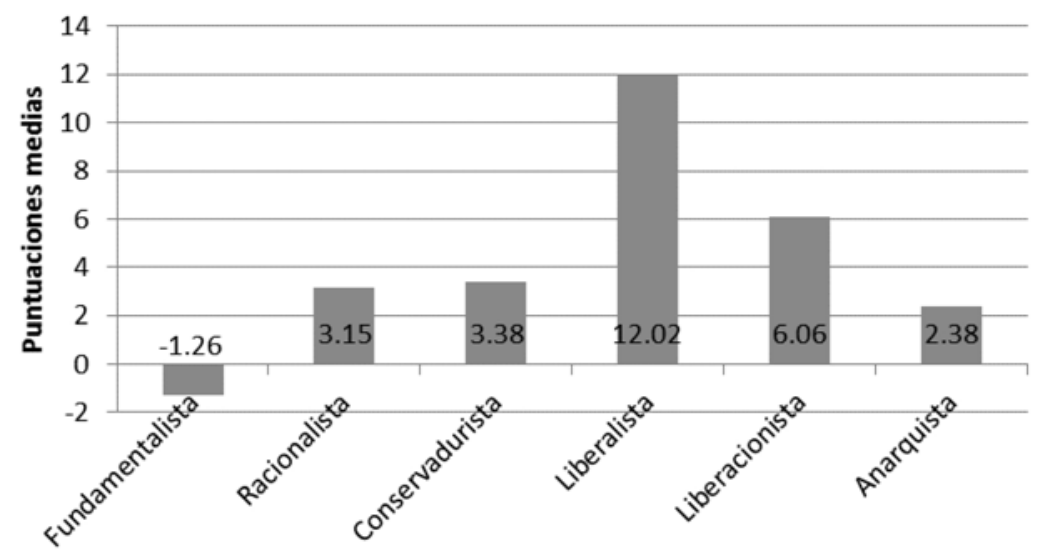

Tipos ideológicos

Con los valores anteriores, la caracterización del perfil ideológico de la muestra conjunta estaría proponiendo que en la perspectiva de los futuros profesores, en la formación de ciudadanía como en toda otra competencia que el sistema educativo pretenda formar, es importante la promoción de una conducta personal efectiva en un mundo cambiante, en donde los recursos tecnológicos y tecnócratas juegan un papel central. Así, la noción del desarrollo científico-tecnológico continúa jugando un papel central en la superación de los retos que como sociedad se enfrentan, perspectiva desprendida del tipo liberalista. El individualismo, el pragmatismo, la eficiencia y la eficacia se puntualizan como valores dominantes en esta perspectiva, desde la cual el ejercicio de la ciudadanía estaría considerando que la elección de los funcionarios más capaces y competentes técnicamente sería el elemento clave para el funcionamiento adecuado de las diversas instituciones de la sociedad. Entonces, un papel importante de la educación en la formación de ciudadanía se encontraría orientado al desarrollo de los individuos más capaces para ciertas tareas preponderantes, y a la sensibilización del resto de los individuos en la identificación de los primeros para que sean ubicados en las responsabilidades pertinentes. Este primer componente ideológi- 
co se encuentra claramente vinculado con la dinámica de una democracia representativa de corte electoral en un modelo de ciudadanía liberal.

Por otra parte, el segundo tipo ideológico dominante (liberacionismo) implicaría una influencia significativa en la perspectiva de los futuros profesores, donde la educación como institución debe jugar en la formación de ciudadanía un papel orientado a la concientización de los individuos y grupos más oprimidos, pero también al desarrollo de habilidades que les permitan planear y ejecutar las acciones políticas y sociales que modifiquen las estructuras que les afectan. La escuela entonces, desde esta perspectiva, se considera un campo de lucha ideológica, social y política. La justicia, la equidad, la solidaridad y el compromiso político en tanto forma de ejercer el poder con la participación de todos los implicados, constituyen los valores dominantes en esta perspectiva desde la cual el ejercicio de la ciudadanía estaría orientado a la participación constante y comprometida para el posicionamiento de los intereses de distintos grupos en la sociedad. Así, un objetivo esencial de la educación en la formación de ciudadanía se ocuparía de desarrollar habilidades sociales vinculadas a una participación política efectiva que permita disminuir las asimetrías entre los sectores de la sociedad por medio de la participación ciudadana en distintos niveles institucionales y también por la conformación de grupos civiles y políticos que jueguen un papel de oposición a las estructuras de poder dominantes. Este segundo componente ideológico tiene relación estrecha con la construcción colectiva del bien común, en tanto elemento de la esfera pública que sustenta la naturaleza de una democracia participativa y un modelo de ciudadanía republicano.

Otros dos tipos ideológicos que representan una menor aunque no desdeñable influencia con respecto a los dos anteriores, son el conservadurista y el racionalista, los cuales sugieren que en la perspectiva de formación de ciudadanía de los futuros profesores, la educación como institución aún debe jugar un papel significativo en la transmisión de patrones de conductas sociales dominantes, motivando el entendimiento y el aprecio por las instituciones y tradiciones culturales contemporáneas de la socie- 
dad mexicana, promoviendo así un significativo respeto por la ley y el orden en sus formas actuales. También sigue presente entre los objetivos de la educación la transmisión del conocimiento en tanto verdad y la valoración de las competencias racionales con énfasis en la lógica deductiva. Valores tradicionales como el respeto por las jerarquías y una identidad nacional homogeneizadora se hacen presentes por medio de estos dos tipos ideológicos. En los objetivos de la educación, desde esta perspectiva, aún se considera de manera sensible que en la formación de ciudadanía es importante destacar el respeto por las instituciones de la sociedad, sustentándolo en buena medida en el estatus jerárquico y en la transmisión de conocimiento basada en la superioridad intelectual de los profesores. La presencia de estos dos componentes de orientación conservadora permite explicar en buena medida la aún menor presencia del tipo ideológico anarquista; el cual representa una fuerte perspectiva de autonomía de los individuos y una transformación radical de los objetivos de la educación en tanto institución proveedora de igualdad social. Por último, la presencia de un distanciamiento del tipo ideológico fundamentalista resulta congruente en la configuración del perfil general, en el cual existe al menos una mínima simpatía por el tipo ideológico anarquista.

Un tercer conjunto de resultados se emplea para analizar contrastes en perfiles ideológicos configurados en función de las variables institución, lugar de procedencia y sexo. Se utilizó la prueba $t$ de Student en muestras independientes para identificar diferencias entre perfiles, y t de Student en muestras relacionadas para diferenciar entre los tipos ideológicos al interior de cada perfil.

Se pueden identificar diferencias estadísticamente significativas (tabla 3) entre las dos instituciones en los tipos ideológicos anarquista, conservadurista, fundamentalista y racionalista, siendo las más pronunciadas las de estos últimos dos tipos. Por otro lado, los tipos ideológicos liberalista y liberacionista se presentan con la misma intensidad en ambas instituciones. En el caso de los estudiantes de la UACJ, su perfil ideológico se encuentra fuertemente matizado por los rasgos liberalista y liberacionista, con diferencia estadística entre ambos, y siendo estos 
dos tipos ideológicos estadísticamente superiores al resto de los tipos ideológicos. En contraste, si bien el perfil de los estudiantes de la uv se encuentra en primer lugar fuertemente matizado por el tipo liberalista, en segundo lugar los tipos ideológicos liberacionista, conservadurista y racionalista influyen el perfil con la misma intensidad (valores estadísticamente iguales). Otros contrastes se observan en el tipo fundamentalista: mientras que los estudiantes de la UACJ presentan un distanciamiento de este tipo, los estudiantes de la uv muestran una mínima empatía por él. Y en el tipo anarquista, el perfil de los estudiantes de la uv muestra una mayor presencia del mismo, mientras que es un rasgo con valores significativamente inferiores en sus similares de la UACJ.

Tabla 3. Contraste de medias de los tipos de ideológicos por instituciones y al interior de ellas

\begin{tabular}{|c|c|c|c|c|c|c|c|c|c|}
\hline 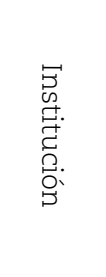 & 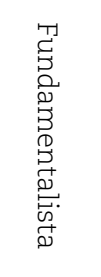 & 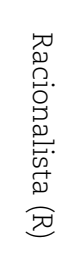 & $\begin{array}{c}\mathrm{t} \\
\text { (sig) } \\
\mathrm{R} \\
\mathrm{y} \\
\mathrm{Ln}\end{array}$ & 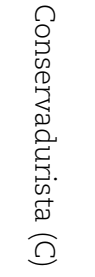 & $\begin{array}{c}\mathrm{t} \\
\text { (sig) } \\
\mathrm{C} \\
\mathrm{y} \\
\mathrm{Ln}\end{array}$ & 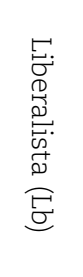 & $\begin{array}{c}\mathrm{t} \\
\text { (sig) } \\
\mathrm{Lb} \\
\mathrm{y} \\
\mathrm{Ln}\end{array}$ & 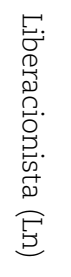 & 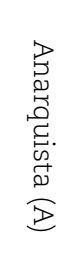 \\
\hline UACJ & -4.33 & 0.34 & \multirow[t]{3}{*}{$\begin{array}{c}-9.439 \\
(.000)\end{array}$} & 1.46 & \multirow[t]{3}{*}{$\begin{array}{c}-5.974 \\
(.000)\end{array}$} & 12.16 & \multirow[t]{2}{*}{$\begin{array}{c}10.999 \\
(.000)\end{array}$} & 6.00 & 1.54 \\
\hline $\mathrm{t}(\operatorname{sig})$ & $\begin{array}{r}-7.649 \\
(.000)\end{array}$ & $\begin{array}{r}-7.83 \\
(.000) \\
\end{array}$ & & $\begin{array}{r}-4.719 \\
(.000) \\
\end{array}$ & & & & & $\begin{array}{r}-2.046 \\
(.042) \\
\end{array}$ \\
\hline UV-Xal & 1.42 & 5.60 & & 5.06 & & 11.90 & $\begin{array}{c}12.599 \\
(.000)\end{array}$ & 6.11 & 3.12 \\
\hline
\end{tabular}

$N=261$ Prueba $t \alpha 0.05$

Estos contrastes mueswtran semejanzas y distinciones significativas en la perspectiva que los estudiantes de ambas instituciones tienen con respecto al papel de la educación en la formación de ciudadanía. En ambos grupos se asigna importancia al conocimiento científico y a los recursos tecnológicos y tecnócratas, en cuanto elemento esencial en la superación de los retos que la sociedad enfrenta. Lo anterior, de alguna manera enfatiza el carácter pragmático, individual y eficientista en la participación de los individuos en el ejercicio de su ciudadanía y en su proceso de formación. En la muestra de estudiantes de ambas instituciones 
existe una fuerte perspectiva sobre la influencia que la educación como institución debe tener, tanto en el desarrollo de habilidades efectivas para la participación política de los grupos sistemáticamente más oprimidos como en la construcción de una sociedad con menos asimetrías. En cuanto a las distinciones, mientras que en la muestra de la UACJ las dos descripciones anteriores son las dominantes, en la muestra de la uv se identifican tres aspectos interesantes: existe una fuerte influencia de la importancia de la jerarquía como elemento base en la transmisión del respeto por las instituciones de la sociedad, una presencia sustancial del discurso intelectualista a la par del pragmatismo en la transformación del contexto y una mayor presencia del rasgo ideológico anarquista que en los alumnos de la UACJ, lo que implica para los alumnos de la uv un importante reconocimiento de la capacidad de autonomía de los individuos para regularse a sí mismos, por sobre la sujeción a instituciones sociales como medio para lograr el beneficio social colectivo.

Los análisis realizados en torno al lugar de procedencia (rural o urbano) y al sexo (masculino o femenino) muestran diferencias solo en algunos tipos ideológicos de manera individual. Para el caso de procedencia, el tipo ideológico racionalista de procedencia rural ( $\bar{X}=5.27)$ muestra un valor superior y estadísticamente significativo $\left[\mathrm{t}_{(259)}=7.747, \mathrm{p} \leq .01\right]$ con respecto del grupo de procedencia urbana $(\bar{X}=2.67)$, mientras que en las muestras por instituciones, el segmento de procedencia rural de la UACj obtiene un puntaje estadísticamente superior $\left[\mathrm{t}_{(120)}=2.136, \mathrm{p} \leq .05\right]$ en el tipo ideológico liberalista ( $\bar{X}=15.86$ ) por sobre su similar de procedencia urbana ( $\bar{X}=11.93$ ); y en cuanto a los estudiantes de la UV, el rasgo ideológico anarquista se presenta significativamente $\left[\mathrm{t}_{(137)}=\right.$ $2.415, \mathrm{p} \leq .05]$ con mayor énfasis en el segmento de procedencia urbana ( $\bar{X}=3.87$ ) en contraste con el de procedencia rural ( $\bar{X}=1.34)$.

En el caso de la variable sexo, en la muestra total la diferencia significativa se presenta en el tipo liberacionista, donde el valor de la media en los hombres $(\bar{X}=8.00)$ es estadísticamente superior $\left[\mathrm{t}_{(259)}=2.324, \mathrm{p} \leq .05\right]$ al de las mujeres $(\overline{\mathrm{X}}=5.71)$. Ahora, si se analiza únicamente al segmento de la población de mujeres y se contrasta el lugar de procedencia, se observa en el tipo ideológico 
racionalista que las mujeres del contexto rural ( $\bar{X}=5.13)$ puntúan significativamente más alto $\left[\mathrm{t}_{(219)}=2.334, \mathrm{p} \leq .05\right]$ que sus pares del contexto urbano $(\bar{X}=2.64)$. Análisis iguales se hicieron para la población de hombres, pero no se identificaron diferencias significativas. Finalmente, al analizar las muestras por instituciones y por sexo, la única diferencia que se identifica es en estudiantes de la UACJ, donde el tipo ideológico liberacionista del sexo masculino $(\bar{X}=8.89)$ presenta un puntaje superior $\left[\mathrm{t}_{(120)}=2.275, \mathrm{p} \leq .05\right]$ por sobre el segmento del sexo femenino $(\bar{X}=5.50)$. Si bien, estos resultados en función del lugar de origen y del sexo nos permiten identificar distinciones que caracterizan a los diversos segmentos analizados, no se observa un patrón que permita seguir algún rasgo característico hasta alguno de los subsegmentos considerados. En este mismo sentido, otras investigaciones tampoco han reportado evidencia de distinciones contundentes en los tipos ideológicos en relación con la variable sexo (Arroyo, 1998; Loera, 2005; Anaya, 2009; Guzmán y Barraza, 2004).

\section{DISCUSIÓN Y CONCLUSIONES}

En la segunda sección de este trabajo se analizó la caracterización de una ciudadanía que resultara funcional con respecto al momento sociopolítico y cultural que actualmente vive la sociedad mexicana, mismo que no resulta privativo de ella. Se identificó que conforme a las dinámicas globales del actual modelo económico capitalista, así como a la caracterización de la forma de convivencia sociopolítica elegida para la organización vigente del estado nacional (la democracia), ciertos rasgos en el ejercicio de la ciudadanía resultarían deseables cuando no indispensables, para que los ideales de la democracia se mantengan en el mejor de los escenarios en una dinámica progresiva o al menos fuera de una involutiva. Así, se consideraron pertinentes rasgos de una ciudadanía con características básicas de un modelo republicano y con ciertos rasgos deseables de otro radical.

En los resultados presentados se identificó, en la perspectiva ideológica de los futuros profesionales vinculados a los contextos educativos, que los objetivos en la formación de ciudadanía se 
siguen manteniendo fuertemente orientados hacia las características de un modelo de ciudadanía liberal, el cual se vincula de manera natural a los intereses del sistema económico capitalista actual. Este aspecto resulta inquietante bajo la consideración de las naturalezas diferentes del capitalismo y la democracia, y en cuanto al objetivo institucional y social de la educación de constituirse en uno de los recursos más significativos e influyentes en la transformación de la actual sociedad mexicana. Sin embargo, también se identificaron otros resultados alentadores, pues otro conjunto de rasgos ideológicos vinculados al tipo liberacionista se identificaron con una intensidad nada desdeñable, situación que puede fortalecer en el mediano plazo el proyecto democrático de la citada sociedad. La presencia importante de estos rasgos en cierta forma divergentes apunta a la configuración diversa de la sociedad mexicana con grupos o sectores que se posicionan en perspectivas distintas. En este sentido, se encuentran presentes rasgos ideológicos que matizan con diferentes intensidades a algunos grupos o regiones del país. Rasgos como el resguardo de las tradiciones socioculturales y políticas, el respeto por las leyes e instituciones basado en la jerarquía, y los discursos articulados bajo la lógica corporativa se encuentran presentes en el conservadurismo y racionalismo ideológicos. Dichos rasgos aún se constituyen en un oponente significativo de la perspectiva liberacionista. Bajo estas condiciones, podríamos lanzar una hipótesis sobre la débil presencia de los ideales democráticos en la perspectiva ideológica de los futuros profesores, aspecto que cuestionaría la viabilidad del impulso desde los sistemas educativos de modelos de formación de ciudadanía con rasgos radicales, situación sostenida en la tímida presencia del anarquismo como ideología educativa.

En la tercera sección del trabajo se efectuó un recorrido breve sobre la consideración del proyecto educativo nacional como instrumento público en la formación de ciudadanía, por medio de las transformaciones del artículo $3 .^{\circ}$ constitucional y otras enunciaciones en algunas leyes secundarias, como la Ley General de Educación. Se expuso que el planteamiento de formación de ciudadanía realizado desde la orientación ideológica del sis- 
tema educativo nacional consideró en sus inicios la urgencia de autonomía, unidad e identidad nacionales, promoviendo valores universales como el respeto, la libertad, la justicia, la unidad y la dignidad humana. Al parecer estos valores se fueron acondicionando por las dinámicas históricas que moldearon a la sociedad mexicana, y probablemente encontraron una forma peculiar de llenarse de contenido durante los 70 años de dominio corporativista y autoritario por un partido que controlaba tanto el gobierno federal como los estatales. Matices de conservadurismo y racionalismo, como por ejemplo la legitimación de las estructuras jerárquicas por medio del tradicionalismo, así como la superioridad intelectual de ciertos grupos, sectores o individuos, y la búsqueda de ideales universales pero homogeneizantes, fueron identificados de manera significativa en la perspectiva ideológica educativa del estudio realizado en el sureste mexicano. Esta situación permite proponer, a un largo tiempo de distancia, la vigencia de ciertas circunstancias que dieron origen a los esfuerzos articulados en el nacimiento de nuestro Estado-nació, pues como se discutió en torno al concepto de ideología, la existencia de algún tipo ideológico supone una vinculación de los sujetos con un entorno material o simbólico caracterizado de forma similar.

Otra influencia ideológica en el proyecto educativo nacional se situó en la función sociopolítica de la educación, bajo la perspectiva de la democracia como una forma de convivencia que asigna un papel fundamental a la voluntad del pueblo, en quien reside finalmente la soberanía nacional. La presencia significativa del tipo ideológico liberacionista en los estudios comentados, dan cuenta de algunos resultados exitosos de este segundo momento de influencia. Así, valores esgrimidos en los artículos constitucionales $3 .^{\circ}, 39 .^{\circ}$ y $40 .^{\circ}$ como la autonomía del pueblo para modificar su forma de gobierno, la democracia y la equidad, entre otros, encuentran referente empírico en este rasgo ideológico, el cual es consistente en los dos contextos donde se verificaron los estudios.

De acuerdo a la posterior y dramática influencia en la perspectiva ideológica del proyecto educativo nacional por la corriente neoliberal del actual sistema capitalista global, el tipo ideológico liberalista se ostenta como el dominante en los estudios expues- 
tos, manifestando en su forma empírica valores contenidos en la última generación de transformaciones del artículo 3. ${ }^{\circ}$ constitucional. Por ejemplo, calidad, máximo logro de aprendizaje (eficacia y eficiencia), progreso científico y tecnológico. Este es otro rasgo consistente en los estudios realizados en ambos contextos.

La educación como institución que participa en la formación de ciudadanía no escapa a las influencias históricas configuradas por acontecimientos políticos, económicos y culturales de ámbitos nacionales y globales. En ella se pueden apreciar inercias que se manifiestan en la configuración ideológica que alrededor de la educación existe y en sus objetivos para formar ciudadanía. Los resultados presentados en este trabajo ofrecen información sobre distinciones que caracterizan dos contextos nacionales geográficos, culturales y con desarrollo económico y social diferentes. Resultan significativas algunas particularidades, como el matiz racionalista asociado a contextos rurales en ambos estudios, la perspectiva liberalista más acentuada en el contexto rural que urbano en el estudio del norte del país o el tipo anarquista, que se destaca mayormente en contextos urbanos que en los rurales en la muestra del sureste mexicano. Otros datos que implican muestras más amplias, así como distintos tipos de instituciones en las mismas entidades, se encuentran actualmente en proceso de análisis. Este tipo de estudios permiten ampliar la discusión sobre las condiciones actuales desde las cuales se plantean los esfuerzos de formación ciudadana, indistintamente de si se realizan desde el sistema educativo y por medio de la política pública nacional o desde los escenarios de la sociedad civil, grupos políticos o académicos. Un proyecto de formación de una ciudadanía para la instauración de la democracia como una forma real de convivencia político-social requiere partir de las condiciones reales, tanto de tipo social como económico o ético, que experimentan los individuos a los cuales se pretende habilitar para que participen activa y efectivamente en tal sistema sociopolítico. De lo contrario, la democracia seguirá manteniéndose como el aliciente para la generación de políticas públicas, programas sociales, campañas políticas o enfoques educativos que sirvan a 
diversidad de intereses siempre ajenos a la propia naturaleza de la democracia.

Si la educación como institución aspira a colaborar en la construcción del proyecto democrático, debe asumir la importancia de considerar, consciente e intencionalmente, el impulso de una ideología en todos los niveles educativos que resulte correspondiente con tal proyecto y, por supuesto, contar con el financiamiento correspondiente. Y en este sentido, una reflexión de autocrítica desde el sistema educativo nos lleva a considerar la vigencia del cuestionamiento sobre si una política educativa tiene como propósito transformar el sistema social (en este caso el mexicano), o es simplemente un intento de restaurar un equilibrio roto ante señas, amenazas y crecientes conflictos (Latapí, 1989).

\section{REFERENCIAS}

Ackerman, B. (1980). Social justice in the liberal state. New Haven: Yale University Press.

Alcántara, M. (1992, enero-marzo). ¿Democracias inciertas o democracias consolidadas en América Latina? Revista Mexicana de Sociología, 54(1), 205-223. Recuperado el 15 de febrero de 2010 de http://www. jstor.org/stable/3540784

Almond, G. y Powell, B. (1996). Comparative politics: a development approach. En A. J. Magri (2006), Gobernabilidad y governance para el desarrollo en las regiones metropolitanas: aportes para una discusión en ciernes. Recuperado el 12 de marzo de 2010 de http://www.aucip.org.uy/docs/ procesos_de_gestion_municipal_y_regional/altair_magri.pdf

Althusser, L. (1985). Ideología y aparatos ideológicos del Estado: notas para una investigación. México: Quinto Sol. Recuperado el 20 de abril de 2010de www.philosophia.cl/EscueladeFilosofiaUniversidadARCIS

Anaya, R. (2009). Razonamiento moral e ideología educativa. Alumnos y profesores de escuela secundaria. En I. Álvarez Olivas (coord.), De la política a la sociedad. 7 reflexiones desde la frontera (pp. 279-300). México: UACJ.

Arroyo, I. (1998). Filosofía de la educación en Chihuahua. Chihuahua, México: Instituto Chihuahuense de la Cultura. 
Barba, B. (2003). La formación de valores y la participación social. En P. Latapí (coord), Un siglo de educación en México (pp. 44-62). México: FCE.

Barba, B. (2004). Escuela y socialización. Evaluación del desarrollo moral. Aguascalientes, México: Universidad Autónoma de Aguascalientes.

Cámara de Diputados (2003). Evolución jurídica del artículo 3. ${ }^{\circ}$ constitucional. Biblioteca electrónica del H. Congreso de la Unión. México. Recuperado de http://www.diputados.gob.mx/bibliot/publica/inveyana/ polint/cua2/evolucion.htm

Cámara de Diputados (2015). Constitución Política de los Estados Unidos Mexicanos. Biblioteca electrónica del H. Congreso de la Unión. México. Recuperado de http://www.diputados.gob.mx/LeyesBiblio/htm/1.htm

Contreras, Escobedo, Quintana y Valdez (2003). La evaluación de los nuevos planes de estudio en la Facultad de Ciencias Químicas de la Universidad Autónoma de Chihuahua. Synthesis. Recuperado el 15 de febrero de 2012 de http://www.uach.mx/extension_y_difusion/ synthesis/2009/01/21/la_evaluacion_de_los_nuevos_planes.pdf

Dahl, R. (1989). La poliarquía. Participación y oposición. España: Tecnos.

Dahl, R. (2003). Entrevista sobre el pluralismo. México: FCE.

De Giovanni, B. (1984). La teoría política de las clases en El Capital. México: Siglo XXI.

Del Valle, S. (14 de julio de 2014). Deja la SEP morir Enciclomedia. Diario Reforma. 14 de julio. Recuperado de http://www.reforma.com/ aplicacioneslibre/preacceso/articulo/default.aspx?id=286782\&ur lredirect=http://www.reforma.com/aplicaciones/articulo/default. aspx?id=286782

Dewey, J. (1995). Democracia y educación. Madrid: Ediciones Morata.

Diario Oficial de la Federación (2015, 20 de abril). Ley General de Educación. México: Cámara de Diputados del Congreso de la Unión. Recuperado de http://www.diputados.gob.mx/ LeyesBiblio/ref/lge/LGE_ ref29_20abr15.pdf

Diario Oficial de la Federación (2013, 26 de febrero). Reformas constitucionales al artículo 3.․ Novena reforma, fracción IX. México: Cámara de Diputados del Congreso de la Unión. Recuperado de http://www.diputados.gob.mx/LeyesBiblio/ref/dof/CPEUM_ref_206_26feb13.pdf

Diario Oficial de la Federación (2012, 9 de abril). Decreto para reformar artículo 9 de la Ley General de Educación. México: Cámara de Diputados del 
Congreso de la Unión. Recuperado de http://www.diputados.gob.mx/ LeyesBiblio/ref/lge/LGE_ref24_09abr12.pdf

Diario Oficial de la Federación (2004, 10 de diciembre). Decreto para reformar diversas disposiciones de la Ley General de Educación. México: Cámara de Diputados del Congreso de la Unión. Recuperado de: http:// www.diputados.gob.mx/LeyesBiblio/ref/lge/LGE__ref05_10dic04.pdf

Diario Oficial de la Federación (2003, 13 de marzo). Decreto para reformar el artículo 7. de la Ley General de Educación. México: Cámara de Diputados del Congreso de la Unión. Recuperado de http://www.diputados.gob.mx/LeyesBiblio/ref/lge/LGE_ref04_13mar03.pdf

Eagleton, T. (1997). Ideología, una introducción. España: Paidós.

Escalante, F. (1992). Ciudadanos imaginarios. En G. Prud'homme (1999), Participación ciudadana y democracia en América Latina. México, DF: IFE.

Fariñas, M. (2004). Globalización, ciudadanía y derechos humanos. España: Dykinson.

Giddens, A. (1991). Sociología. Madrid: Alianza.

González-Casanova, P. (1969). Sociología de la explotación. México: Siglo XXI. Guzmán, A. y Barraza, L. (2004). La ideología educativa de los formadores de docentes de Durango. IX Congreso Nacional de Investigación Educativa. Memoria electrónica. Recuperado el 17 de enero de 2012 de http://www.comie.org.mx/congreso/memoria/v9/ponencias/at16/ PRE1178923039.pdf

Hayek, F. (1960). The constitution of liberty. Chicago: The University of Chicago Press.

Hernández, R., Fernández, C. y Baptista, P. (2006). Metodología de la investigación (4. ${ }^{a}$ edición). México: McGraw Hill

Illich, I. (1985). La sociedad desescolarizada. México: Posada.

Knight A., K., y Harnish, J. (2006). Contemporary discourses of citizenship. Review of Educational Research, 76(4). Recuperado el 3 de mayo de 2010 de $<$ http//www.jstor.org/stable/4124417>.

Latapí, P. (1989). Política educativa y valores nacionales. México: Nueva Imagen, $7 .^{\mathrm{a}}$ ed.

Lebowitz, M. (2005). Más allá de El Capital. La economía política de la clase obrera en Marx. Madrid: Akal.

Linz, J. (1978). Una teoría del régimen autoritario. El caso de España. En S.

Payne, S. Política y sociedad en la España del siglo XX. Madrid: Akal.

Lipovetski, G. (2002) La era del vacío. España: Anagrama. 
Llinás, E. (1978) Revolución, educación y mexicanidad. México: UNAM.

Loera, A. (2005). Filosofía educativa de los maestros de las escuelas del programa escuelas de calidad. Reportes Nacionales fase 3, Evaluación cualitativa del programa escuelas de calidad. México: SEP.

Marshall, T. y Bottomore, T. (2005). Ciudadanía y clase social. Buenos Aires: Losada.

Meneses, E. (dir.). (1988). Tendencias educativas oficiales en México. 19111934. Ciudad de México: CEE.

Meyer, L. (1992). La segunda muerte de la revolución mexicana. México: Cal y Arena.

Monreal, R. (2014). Privatización del petróleo. El robo del siglo. México: D3 ediciones, S.A. de C.V.

Morlino, L. (1986). Consolidación democrática. Definición, modelos, hipótesis. En M. Alcántara (1992), ¿Democracias inciertas o democracias consolidadas en América Latina? Revista Mexicana de Sociología, 54(1), 205-223. Recuperado el 15 de febrero de 2010 de http://www.jstor.org/ stable/3540784

Mouffe, C. (comp.). (1992). Dimensions of radical democracy: pluralism, citizenship, community. Londres: Verso.

Navarro, A. (2006). Antecedentes de educación. Temas sociales de la agenda legislativa. Centro de Estudios Sociales y de Opinión Pública. Recuperado el 16 de julio de 2012 de http://archivos.diputados.gob.mx/Centros_Estudio/Cesop/Comisiones/2_educacion.htm.

Newman, J. (2005). Remaking governance: peoples, politics, and the public sphere. European Social Policy Association Research Network. Bristol: Policy Press.

O'Neill, W. (1981). Educational ideologies: contemporary expressions of educational philosophy. Santa Mónica, Ca: Goodyear Publisching Co.

Olvera, A. (2008). Ciudadanía y democracia. México: IFE.

Ornelas, C. (1995). El sistema educativo mexicano. La transición de fin de siglo. México: FCE, CIDE, Nafinsa. 8. ${ }^{a}$ reimpresión, 2002.

Petras, J. y Veltmeyer, H. (2004). El sistema en crisis. España: Editorial Popular.

Poder Ejecutivo Federal (1983). Plan Nacional de Desarrollo 1980-1982. México: Talleres Gráficos de la Nación.

Rapoport, M. y Brenta, N. (2010). Las grandes crisis del capitalismo contemporáneo. Argentina: Capital Intelectual. 
Rawls, J. 1996. Liberalismo político. Madrid: Crítica.

Sánchez, L. (1996). Las relaciones entre la gobernabilidad democrática y el sistema educativo: un estado de la cuestión. Revista Iberoamericana de Educación 29(12), 79-103.

Sartori, G. (1994). Teoría de la democracia. 1. El debate contemporáneo. España: Alianza.

Sartori, G. (2009). La democracia en 30 lecciones. México: Santillana.

SEP (2006). Programa Enciclomedia. Libro blanco. México: Secretaría de Educación Pública.

SEP (2008). Programa integral de formación cívica y ética para la educación básica. México, DF: Subsecretaría de Educación Básica.

Touraine, A. (2002). Igualdad y diversidad. Las nuevas tareas de la democracia. España: FCE.

Vázquez, J. (1975). Nacionalismo y educación en México. México: El Colegio de México. 2. ${ }^{\mathrm{a}}$ ed. 